\title{
Магнитный резонанс в наночастицах гадолиния вблизи температуры Кюри
}

\author{
(C) В.И. Петинов, ${ }^{1}$ В.В. Дрёмов ${ }^{2}$ \\ ${ }^{1}$ Институт проблем химической физики РАН, \\ 142432 Черноголовка, Московская обл., Россия \\ ${ }^{2}$ Институт фризики твердого тела, \\ 142432 Черноголовка, Московская обл., Россия \\ e-mail: vip_38@mail.ru
}

(Поступило в Редакцию 26 июня 2017 г.)

Исследовано влияние температуры в области $275<T<320 \mathrm{~K}$ на ЭПР и намагниченность $m$ ансамблей сферических наночастиц Gd диаметром от 89 и до $18 \mathrm{~nm}$. У наночастиц $d=18 \mathrm{~nm}$ была ГЦК структура и отсутствовал магнитный переход. При $T>T_{\mathrm{C}}$ все наночастицы были парамагнитными и независимо от

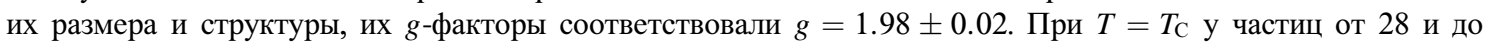
$89 \mathrm{~nm}$ происходили магнитный и ориентационный переходы и при $T<T_{\mathrm{C}}$ их $m(H)$ имели вид функции Ланжевена, а линии ФМР уширялись и сдвигались в направление $H=0$. Линии ФМР ансамблей частиц $\mathrm{Gd}$ при перемагничивании проявляли гистерезисное поведение, не связанное с коэрцитивностью частиц. Зависимости ширины $\Delta H(T)$ линий ФМР наночастиц $\mathrm{Gd}$ изменялись пропорционально $\left|T-T_{\mathrm{C}}\right|$.

DOI: $10.21883 /$ JTF.2018.04.45721.2392

\section{Введение}

Согласно сложившимся на сегодняшний день представлениям, магнетизм гадолиния ниже температуры Кюри $T_{\mathrm{C}}$ и сильный парамагнетизм выше $T_{\mathrm{C}}$ обусловлены $4 f$-электронами. Прямое взаимодействие между этими электронами даже соседних ионов маловероятно, так как расстояние между ними почти на порядок больше радиуса $4 f$-оболочки. Поэтому предполагается, что обменное взаимодействие $4 f$-электронов разных ионов гадолиния осуществляется косвенно через поляризацию электронов проводимости. На основе такой модели о характере электронного взаимодействия в редкоземельных металлах (РЗМ) была построена теория РККИ (Рудермана-Киттеля-Касуйи-Иосиды) [1].

Принимая эту теорию магнетизма для Gd в качестве основной и допуская, что его можно рассматривать как обычный коллинеарный ферромагнетик, у которого $4 f$ электроны спрятаны в глубине иона, были разработаны теории ЭПР в гадолинии, предсказывающие величину $g$ фактора и особый характер изменения сигнала ЭПР в $\mathrm{Gd}$ вблизи $T_{\mathrm{C}}[2-4]$.

Первые температурные исследования ЭПР в Gd были проведены вблизи $T_{\mathrm{C}}$ практически одновременно на частотах $9 \mathrm{GHz}[5]$ и $32 \mathrm{GHz}[6]$. В этих экспериментах использовались монокристаллы $\mathrm{Gd}$ размером в несколько mm, в том числе подвергнутые деформации [6]. Но результаты этих работ оказались разными, даже противоречивыми. Так, в [5] зависимость ширины линии $\Delta H(T)$ имела максимум вблизи $T_{\mathrm{C}}$, а в работе [6] у аналогичного монокристалла подобная особенность в зависимости $H(T)$ отсутствовала. Ниже $T_{\mathrm{C}}$ в работе [6] $\Delta H$ просто плавно увеличивалась, без каких-либо особенностей.
Известно, что благодаря скин-слою $\delta$ (у гадолиния $\delta \sim 10^{-5} \mathrm{~m}$ на частоте $\left.10 \mathrm{GHz}\right)$ имеет место неоднородное распределение высокочастотного поля по объему проводящего образца. Если его размер больше $\delta$, то спектр ЭПР заметно искажается из-за диффузии электронов проводимости в неоднородном высокочастотном поле скин-слоя. Для установления истиной ширины линии ЭПР металлических макрокристаллов приходится использовать корректирующие формулы Дайсона (см. например, [7]). Они позволяют учитывать изменение комплексной магнитной проницаемости $\mu^{*}$ при магнитном переходе. Но в области $T_{\mathrm{C}}$ проницаемость $\mu^{*}$ и намагниченность $\mathrm{Gd}$ изменяются скачком, поэтому из-за магнитного перехода аналогичная метаморфоза проистекает и со скин-слоем. Все это вносит неопределенность как в коррекцию формы линии ЭПР по Дайсону, так и в размагничивающий фактор макроскопических образцов $\mathrm{Gd}$.

Сравнительно недавно опубликована работа [8], в которой образец гадолиния для ЭПР исследований был получен в ультрадисперсном состоянии путем последовательного механохимического воздействия вначале на смесь частиц $\mathrm{Gd}$ размером $\sim 300 \mu \mathrm{m}$ и $\mathrm{SiO}_{2}$ размером $44 \mu \mathrm{m}$, а затем на смесь этих частиц с полистиролом. По мнению авторов [8], им удалось из гадолиния произвести магнитные кластеры, состоящие из нанокристаллов размером $30 \mathrm{~nm}$. Полученная в этой работе зависимость $\Delta H(T)$ имела характер, подобный тому, какой ранее был обнаружен в работе [6], т.е. происходило плавное увеличение $\Delta H(T)$ при переходе $T_{\mathrm{C}}$, и характер этой зависимости не изменялся при дальнейшем понижении температуры.

В настоящей работе была поставлена цель: исследовать особенности перехода в ферромагнитное состо- 
яние сферических наночастиц $\mathrm{Gd}$ методом ЭПР при одновременной регистрации намагниченности образцов с размером частиц от 89 до $18 \mathrm{~nm}$. Ранее [9] при исследовании структуры и $T_{\mathrm{C}}$ наночастиц $\mathrm{Gd}$ обнаружено, что если их размер равен или превышает $28 \mathrm{~nm}$, большая часть частиц сохраняют ГПУ структуру и проявляют ниже $T_{\mathrm{C}}$ ферромагнитные свойства. В то же время у наночастиц размером $18 \mathrm{~nm}$ происходил ГПУ $\rightarrow$ ГЦК структурный переход и соответственно у них исчезал магнитный переход [9], т. е. частицы сохраняли ниже $T_{\mathrm{C}}$ свои парамагнитные свойства. Кроме того, ранее [10] обнаружено, что при переходе $T_{\mathrm{C}}$ наночастицы Gd c ГПУ структурой приобретают анизотропию типа „легкая плоскость“, которая совпадает с базисной $x-y$-плоскостью Gd [11].

Таким образом, вместо одноосной магнитной анизотропии с константой $K_{1}>0$, характерной для макрокристалла $\mathrm{Gd}$, у наночастиц изменяется знак первой константы $\left(K_{1}<0\right)$ и таким образом они сразу ниже $T_{\mathrm{C}}$ приобретают тот тип анизотропии, который у макрокристалла Gd проявляется только ниже $240 \mathrm{~K}$.

Естественно, возник определенный интерес к исследованию возможного влияния такого типа анизотропии как на намагниченность ансамбля наночастиц $\mathrm{Gd}$, так и на спектр ФМР в них при переходе наночастиц в ферромагнитное состояние. Для этого была разработана специальная методика синхронной регистрации намагниченности ансамбля наночастиц Gd и ФМР спектров в них.

В настоящей работе исследовали ансамбли наночастиц $\mathrm{Gd}$, размер которых во много раз меньше скинслоя $\delta$, и поэтому влиянием неоднородности СВЧ поля в наночастицах можно было пренебречь.

Нельзя не отметить, что наночастицы гадолиния представляют также определенный прагматический интерес. Возможности использования наночастиц гадолиния в технике [12] и особенно в медицине $[13,14]$ стимулируют углубленное изучение их физического состояния, в частности, влияние размера наночастицы на $T_{\mathrm{C}}$ и на их магнетизм вблизи $T_{\mathrm{C}}$. Большая величина магнитного момента атома Gd открывает возможности по созданию на его основе ряда эффективных контрастирующих агентов, в том числе для магниторезонансной томографии. Кроме того, аномально большое сечение захвата тепловых нейтронов ядром Gd стимулирует исследования по возможному использованию его в нейтронно-захватной терапии рака $[15,16]$. Этому должно способствовать и то, что наночастицы Gd являются уникальным ферромагнетиком, у которого переход в ферромагнитное состояние находится в области комнатных температур. И это открывает реальную перспективу для создания управляемых способов ввода в локальные области живого организма и вывода из них наночастиц $\mathrm{Gd}$ за счет всего лишь использования приемлемых градиентов магнитного поля и температуры.

\section{1. Экспериментальная методика}

В исследованиях были использованы образцы наночастиц $\mathrm{Gd}$, размер которых изменялся от от 89 до $18 \mathrm{~nm}$. Частицы были получены конденсацией паров Gd в потоке высокочистого гелия способом Гена-Миллера [17]. Основную сущность этого способа демонстрирует рис. 1, где изображена принципиальная схема основной части установки для получения наночастиц $\mathrm{Gd}$ (рис. 1,a), а на фотографии (рис $1, b)$ представлен ее высокотемпературный узел в процессе производства наночастиц Gd.

Вначале методом электромагнитной левитации в кварцевой трубке 1 подвешивалась навеска гадолиния 2 массой 4-5g, которая после плавления приобретала форму капли, близкой к сферической. В течение всего процесса испарения гадолиния капля непрерывно питалась проволокой гадолиния 3 с помощью бесконтактной магнитной системы 4. Левитация и испарение жидкой капли $\mathrm{Gd}$ обеспечивались электромагнитным полем, создаваемым несимметричным индуктором 5, энергия к которому поступала от высокочастотного генератора. Отличительной особенностью используемого в работе способа было то, что пары гадолиния из высокотемпературной зоны выносились в более холодную область конденсации потоком высокочистого гелия. Газовый поток производился испарением жидкого гелия в транспортном гелиевом сосуде 10 и по безразъемной кварцевой трубке 9 направлялся непосредственно к испаряемой капле гадолиния. Такой метод формирования потока из высокочистого гелия позволил свести до минимума по-

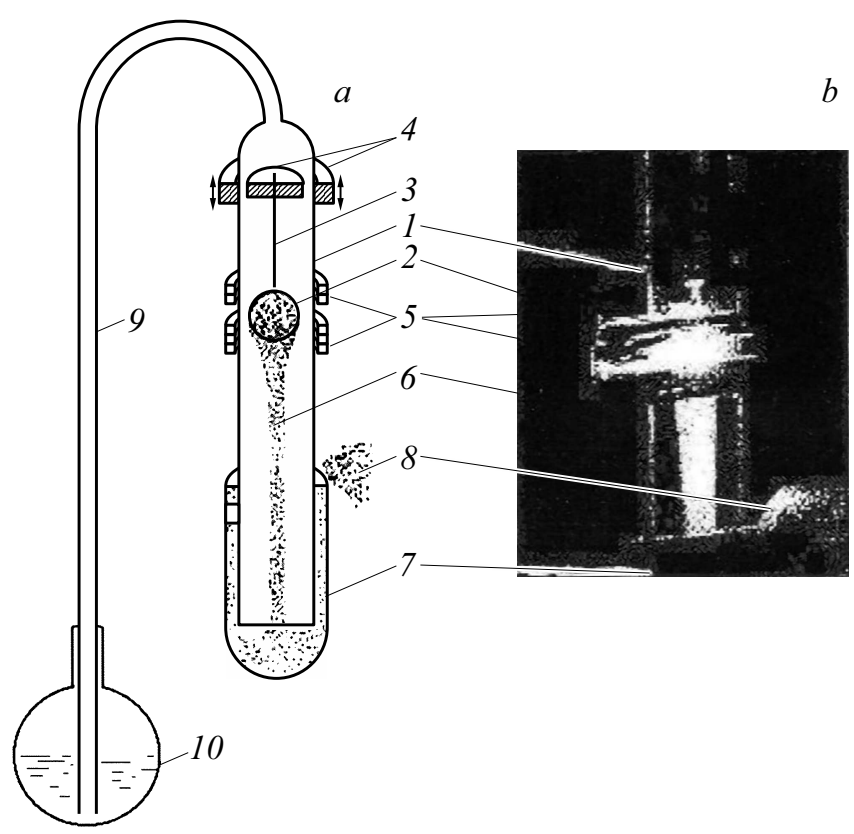

Рис. 1. Схематичное изображение устройства для получения наночастиц $\mathrm{Gd}$ по технологии Гена-Миллера $(a)$ и фотография ее высокотемпературной части $(b)$ в процессе получения наночастиц. Цифровое обозначение ее узлов пояснено в тексте работы. 


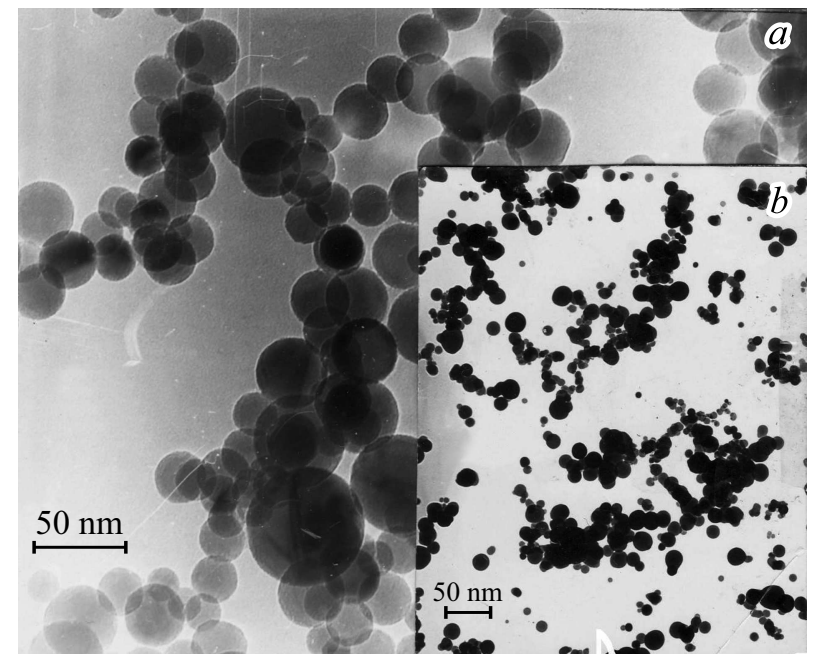

Рис. 2. Электронномикроскопичесие фотографии наночастиц $\mathrm{Gd}$ со среднеобъемным размером $d=64 \mathrm{~nm}(a)$ и $d=18 \mathrm{~nm}(b)$.

явление в нем примеси таких химически активных газов, как $\mathrm{O}_{2}, \mathrm{H}_{2}, \mathrm{H}_{2} \mathrm{O}, \mathrm{N}_{2}$, которые в принципе способны повлиять на химический состав и физическое состояние наночастиц $\mathrm{Gd}$.

Конденсация паров металлов в потоке инертных газов открыла возможность получать наночастицы правильной сферической формы. Из приведенных для примера фотографий наночастиц $\mathrm{Gd}$ размером $64 \mathrm{~nm}$ (рис. 2,a) и $18 \mathrm{~nm}$ (рис.2, $b$ ) видно, что все частицы действительно имеют сферическую форму.

На размер наночастиц по технологии Гена-Миллера можно влиять путем изменения трех взаимно связанных факторов: скоростью испарения металла, скоростью потока инертного газа и изменением его состава.

Разброс по размеру сферических по форме наночастиц гадолиния, как и других металлов и сплавов, получаемых способом Гена-Миллера, был сравнительно узким [9]. Их гистограммы по своему характеру подобны распределениям случайных величин с левосторонним ограничением, математическое представление которых ближе всего соответствует трехпараметрическому гамма-распределению с функцией плотности вероятности [18].

Основные физические свойства, такие как намагниченность и интенсивность спектров ЭПР и ФМР, которые исследуются в настоящей работе, зависят от сложения в эти свойства объемного вклада каждой индивидуальной частицы в образце. Такой образец в принципе теперь может характеризоваться среднеобъемным размером наночастиц в нем. Он экспериментально устанавливался путем усреднения реальных размеров 500-600 наночастиц на фотоснимках, полученных с помощью электронного микроскопа, используя формулу:

$$
\left\langle d_{v}\right\rangle=\left\{\sum n_{i} \cdot d_{i}^{3} / \sum n_{i}\right\}^{1 / 3},
$$

где $n_{i}-$ количество частиц диаметром $d_{i}$. Суммирование осуществляется по всем частицам на фотоснимке.

В работе всюду вместо термина „среднеобъемный размер наночастиц“ для краткости используется упрощенный термин „размер наночастиц“, при этом всегда подразумевая среднеобъемный диаметр наночастиц $\left\langle d_{v}\right\rangle$.

Понятно, что для построения функции распределения наночастиц по размеру и последующего определения их среднеобъемного размера необходимо провести анализ фотографий с большим числом наночастиц. Это осуществлялось следующим образом. В какой-то момент часть потока 6, несущего наночастицы (рис. 1), перед введением их в парафин кратковременно перекрывалась электронно-микроскопической сеткой с нанесенной на ней тонкой углеродной пленкой. Затем полученный на пленке осадок частиц в защитной среде переносился в электронный микроскоп, где осуществлялось фотографирование соответствующих участков пленки с удобно расположенными наночастицами.

С целью предотвращения контакта наночастиц с воздухом они сразу после конденсации паров Gd с помощью потока гелия вводились в обезгаженный жидкий парафин. Для этого поток гелия, выносящий наночастицы из области конденсации паров гадолиния, пропускался сквозь расплавленный парафин 7 (рис. 1). В результате заметная доля наночастиц Gd задерживалась в жидком парафине, а остальные попадали в „выхлоп“ 8 , где часть из них сгорала при контакте с воздухом. Так как температура плавления парафина была близка $65^{\circ} \mathrm{C}$, сформировавшиеся в потоке гелия наночастицы $\mathrm{Gd}$ естественно находились в парамагнитном состоянии, и магнитостатическое взаимодействие между ними было сравнительно малым. После охлаждения и отверждения парафина в нем формировалась устойчивая взвесь наночастиц Gd. В твердом парафине они могли длительное время храниться без видимых следов окисления.

Более детально способ получения наночастиц Gd, используемых в настоящей работе, а также влияние их размера и примеси кислорода на их структуру, а также на высокочастотную магнитную проницаемость и анизотропию описаны в $[9,10]$. Образцы для исследования магнитных свойств и магнитного резонанса представляли собой взвесь наночастицах Gd в твердом парафине, из которой формовали пластины размером $4 \times 4 \times 0.5 \mathrm{~mm}$ и располагали в герметичных тонкопленочных контейнерах из пищевого полиэтилена.

Для изучения магнетизма наночастиц близ $T_{\mathrm{C}}$ была разработана, как отмечалось выше, специальная методика синхронной, т.е. одновременной регистрации перехода одного и того же ансамбля частиц $\mathrm{Gd}$ в магнитно-упорядоченное состояние как по изменению его намагниченности, так и по поглощенной в нем СВЧ энергии в условиях магнитного резонанса. Для этого был модернизирован вибрационный магнитометр (BHV-30 фирмы Riken Denshi) с целью совмещения его с устройством регистрации ЭПР на частоте $9.26 \mathrm{GHz}$. Объединяющим элементом новой установки стал СВЧ 


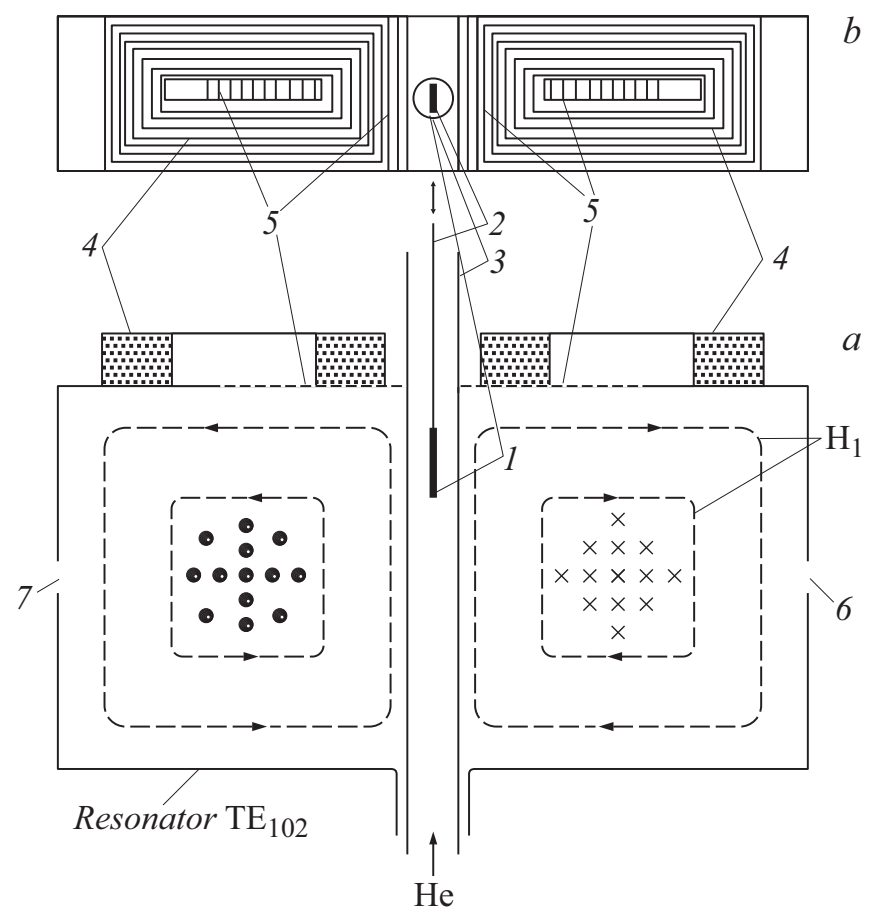

Рис. 3. Схематичное изображение СВЧ резонатора (тип колебаний $\mathrm{TE}_{102}$ ), объединенного с измерительными катушками датчика магнитометра: $a-$ разрез резонатора, $b-$ вид резонатора сверху. Цифровое обозначение пояснено в тексте.

резонатор с укрепленными на нем двумя плоскими измерительными катушками вибрационного магнитометра (рис. 3). Резонатор с типом колебаний $\mathrm{TE}_{102}$ изготовили из отрезка прямоугольного волновода сечением $23 \times 10 \mathrm{~mm}^{2}$. Он жестко крепился в центре между полюсами электромагнита магнитометра. Направление переменного СВЧ поля $H_{1}$ резонатора было перпендикулярно по отношению к магнитному полю электромагнита. Измерительные катушки 4 вибрационного магнитометра имели по $2.5 \cdot 10^{3}$ витков и приклеивались к верхней узкой части резонатора таким образом, чтобы плоскость их витков была параллельна направлению внешнего магнитного поля. Образец 1 располагался в тонкостенном полиэтиленовом контейнере, который в свою очередь присоединялся к кварцевому стержню магнитометра 2. Другой конец стержня имел жесткую связь с механическим вибратором магнетометра. Образец крепился к кварцевому стержню таким образом, чтобы минимизировать его размагничивающее поле, т.е. его большая плоскость была параллельна как постоянному полю $H$, так и переменному $H_{1}$ резонатора. СВЧ колебания в резонаторе возбуждались за счет мощности, поступающей от клистрона по волноводному тракту через щель 6 в торце резонатора, а через другую щель 7 осуществлялась его связь с детекторной секцией. Величину СВЧ мощности можно было регулировать с помощью аттенюатора в пределах 0.1-2 mv. С целью улучшения сцепления рассеянного магнитного потока, создаваемого вертикально вибрирующим образцом 1 с витками измерительных катушек 4 магнитометра, и уменьшения потерь из-за вихревых токов на узкой стенке резонатора, на которой располагались измерительные катушки магнитометра, прорезались поперечные щели 5 шириной $1 \mathrm{~mm} \mathrm{c}$ шагом $2 \mathrm{~mm}$. Наличие таких щелей в резонаторе на его добротность практически не отразилось. После полировки посеребренной внутренней поверхности резонатора и прорезания соответствующих отверстий на его поверхности добротность резонатора $Q$ сохранялась на уровне $10^{3}$ в ненагруженном состоянии. При помещении внутрь резонатора образца с наночастицами гадолиния его добротность падала в пределах $0.5-0.8 \%$ в зависимости от положения образца внутри резонатора.

Низкочастотная вибрация образца вдоль осевой линии резонатора вызывала амплитудную модуляцию $H_{1}$ компоненты СВЧ поля резонатора и соответственно модуляцию его добротности. В конечном итоге это проявлялось в модуляции СВЧ мощности, пришедшей на детектор. Низкочастотный сигнал детектора в условиях автоматической подстройки частоты клистрона после узкополосного усиления регистрировался в виде зависимости поглощенной образцом высокочастотной мощности $P$ от магнитного поля $H$. Вибрация магнитного момента образца в резонаторе одновременно создавала модуляцию магнитного потока в измерительных катушках 4. Низкочастотное напряжение, соответствующее частоте вибрации образца, после усиления и синхронного детектирования регистрировалось в виде зависимости магнитного момента образца $m$ от магнитного поля $H$.

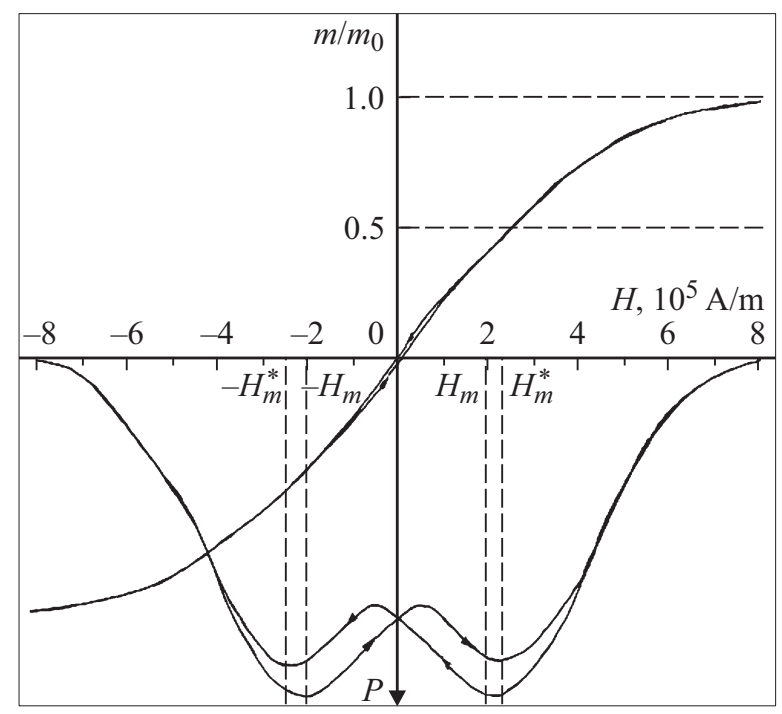

Рис. 4. Зависимости намагниченности $m / m_{0}$ от $H$ и интенсивности $P$ спектра ФМР в ансамбле наночастиц $\mathrm{Gd}$ от $H . T=162 \mathrm{~K} ; d=89 \mathrm{~nm}$. $H_{m}^{*}$ - магнитное поле, соответствующее максимуму $P$ при прямом цикле намагничивания, начинающего от $\left|H_{\max }\right|$ до 0 , и $\left|H_{\max }^{*}\right|$ - также поле максимума в цикле намагничивания образца, когда соответствующее изменение $H$ проведено в отрицательную область $H$ : от 0 до $-\left|H_{\max }\right|$. 


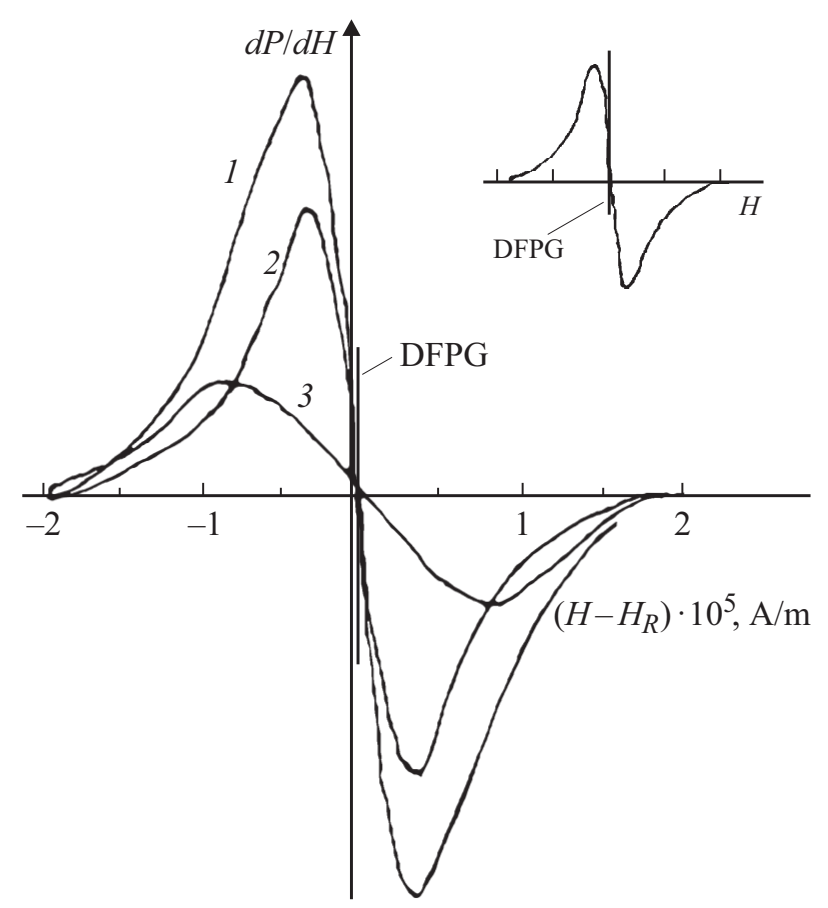

Рис. 5. Производные линий ЭПР в ансамблях наночастиц $\mathrm{Gd}$ размером: $d=47(1), 28$ (2), $18 \mathrm{~nm}$ (3), а на вставке для $d=89 \mathrm{~nm}$. Спектры для $d=18$ и $d=89 \mathrm{~nm}$ записаны одновременно с ЭПР в кристаллах DFPG.

Температура наночастиц определялась с помощью термопары, впрессованной непосредственно в объем образца. Регулировалась она изменением температуры потока паров гелия в двустенной стеклянной трубке 3 с вакуумной изоляцией (рис. 3). Температуру паров Не в свою очередь можно было изменять в пределах 45-330 K путем нагрева с помощью двух нагревателей паров гелия, поступающих непосредственно из транспортных сосудов Дьюара. Обычно стабильность температуры образцов в процессе одного измерения длительностью $\sim 200 \mathrm{~s}$ обеспечивалась с точностью $\pm 1{ }^{\circ} \mathrm{C}$.

На рис. 4 в качестве примера приведены синхронно записанные при $T=162 \mathrm{~K}$ по описанной выше методике зависимость намагниченности $m(H)$ в относительных единицах и спектр ферромагнитного резонанса $P(H)$, полученные на одном и том же образце наночастиц Gd $(d=89 \mathrm{~nm})$ при перемагничивании его в магнитном поле от $+8 \cdot 10^{5}$ до $-8 \cdot 10^{5} \mathrm{~A} / \mathrm{m}$ и обратно до $+8 \cdot 10^{5} \mathrm{~A} / \mathrm{m}$.

\section{2. Экспериментальные результаты}

В работе [10] было показано, что под влиянием магнитного поля, когда его величина превышает $10^{5} \mathrm{~A} / \mathrm{m}$, температурные зависимости намагниченности в области $T_{\mathrm{C}}$ как макроскопического образца, так и наночастиц Gd заметно размываются. С целью уменьшение влияния этого фактора на намагниченность и линию ЭПР необходимо сдвинуться в парамагнитную область как можно дальше от $T_{\mathrm{C}}$. Для этого образцы нагревались, но не более $50^{\circ} \mathrm{C}$, так как при более высоких температурах образцы, состоящие из взвеси наночастиц $\mathrm{Gd}$ в парафине, иногда размягчались и начинали терять свою первоначальную форму.

Экспериментальные исследования ЭПР в наночастицах $\mathrm{Gd}$ диаметром 89, 64, 47, 28 и $18 \mathrm{~nm}$ показали, что в парамагнитном состоянии сигналы ЭПР всех исследованных наночастиц Gd при изменении их размера практически не отличались как по $g$-фактору, так и по своей форме. Однако при уменьшении размера наночастиц все-таки происходит заметное уменьшение интенсивности сигнала ЭПР и его уширение, главным образом в области ниспадающих участков кривых ЭПР. На рис. 5 в качестве для примера приведены линии магнитного резонанса в виде производной резонансных

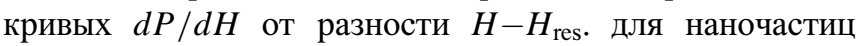
Gd размером 47 (1), 28 (2) и $18 \mathrm{~nm}$ (3). Метка, соответствующая сигналу ЭПР от кристаллика ДФПГ (дифенил-пикрил-гидразил) с $g$-фактором, равном 2.004, регистрировалась одновременно с образцом наночастиц размером $18 \mathrm{~nm}$, а на вставке он записывался одновременно со спектром ЭПР наночастиц размером $89 \mathrm{~nm}$. Из сопоставления положения линии ЭПР образца ДФПГ относительно максимума линии ЭПР наночастиц Gd размером $18 \mathrm{~nm}$, обладающих решеткой с ГЦК симметрией и не проявляющих ферромагнитные свойства ниже $T_{\mathrm{C}}$, установлено, что $g$-фактор наночастиц Gd с кубической решеткой соответствует $g=1.98 \pm 0.02$. Отметим, что спектр 3 сдвинут в сторону больших полей на 400 A/m специально, чтобы оттенить положение линии ДФПГ относительно пересечения спектром 3 оси магнитного поля.

В то же время, как видно из вставки на рис. 5 для наночастиц размером $89 \mathrm{~nm}$, имеющих ГПУ структуру и ниже $T_{\mathrm{C}}$ переходящих в ферромагнитное состояние, $g$ фактор тоже имеет такое же значение: $g=1.98 \pm 0.02$.

Таким образом, можно считать, что экспериментально установлено:

a) у наночастиц Gd с ГПУ структурой $(d \geq 28 \mathrm{~nm})$ и с ГЦК структурой $(d \leq 18 \mathrm{~nm}) g$-факторы практически совпадают с точностью до $1.0 \%$;

b) эти значения $g$-факторов $(g=1.98 \pm 0.02)$ для наночастиц с различающимися симметриями кристаллических структур практически совпадают по величине с $g=1.97 \pm 0.02$ для макрокристаллов гадолиния $[5,19]$. Установленные величины $g$-факторов для наночастиц $\mathrm{Gd}$ с различающимися симметриями кристаллических структур, его монокристаллов [5] и поликристаллических образцов [19] практически совпадают в пределах погрешности их определения с теоретическим значением $g=2.00$ для $4 f$-электронов иона $\mathrm{Gd}^{+3}$, находящегося в $S$-состоянии, и близки к экспериментальной величине $g=1.991$ для этих ионов (см. в работе [1] табл. 1.5 и 1.10).

Все это подтверждает, что никакие химические связи и структурные переходы не оказывают существенного 


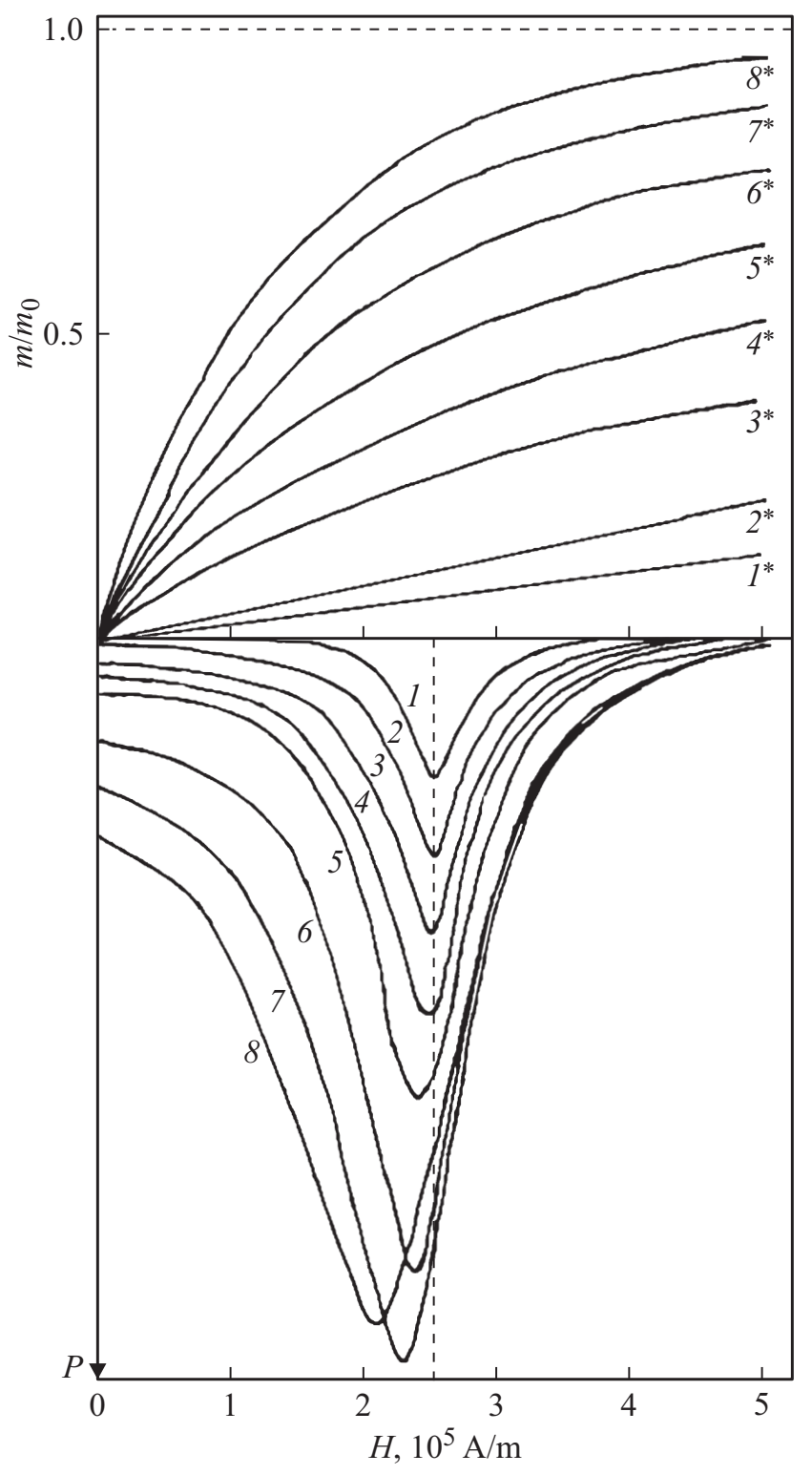

Рис. 6. Зависимости относительной намагниченности $\mathrm{m} / \mathrm{m}_{0}$ от $H\left(1^{*}-8^{*}\right)$ и магнитного резонанса $P(H)(1-8)$ вблизи $T_{\mathrm{C}}$ ансамбля наночастиц $\mathrm{Gd}(d=64 \mathrm{~nm})$ при разных температуpax, K: $1,1^{*}-318 ; 2,2^{*}-314 ; 3,3^{*}-306 ; 4,4^{*}-294$; $5,5^{*}-290 ; 6,6^{*}-286 ; 7,7^{*}-280 ; 8,8^{*}-276$.

влияния на состояние внутренних $4 f$-оболочек атомов гадолиния.

Пример изменения магнитного состояния наночастиц $\mathrm{Gd}(d=64 \mathrm{~nm})$, имеющих ГПУ структуру, демонстрирует рис. 6. На нем представлены полученные одновременной регистрацией намагниченности в относительных единицах $m(H) / m_{0}\left(m_{0}-\right.$ магнитный момент образца при $T=276 \mathrm{~K}$ и $\left.H=8 \cdot 10^{5} \mathrm{~A} / \mathrm{m}\right)$ и спектры ЭПР ансамблей наночастиц $d=64 \mathrm{~nm}$ в виде интенсивности поглощения СВЧ энергии $P(H)$ на одном и том же образце при дискретном понижении его температуры от 320 до $276 \mathrm{~K}$. Зависимости $m(H)$ и $P(H)$ приведены для образца, содержащего $\sim 1 \%$ наночастиц Gd. Магнитное поле $H$ уменьшалось от $8 \cdot 10^{5} \mathrm{~A} / \mathrm{m}$ до 0 . Сразу отметим, что подобный характер имели также зависимости $m(H)$ и $P(H)$ для наночастиц $\mathrm{Gd}$ размером 89,47 и $28 \mathrm{~nm}$, у которых интенсивность соответствующих сигналов заметно падала с уменьшением их размера. Возможно, это связано с ростом доли парамагнитной ГЦК фазы в ансамблях наночастиц $\mathrm{Gd}$ и соответственно с падением доли ГПУ фазы при уменьшении размера наночастиц [9].

Хотя зависимости $m(H) / m_{0}$ и $P(H)$ были получены при уменьшении $H$ после предварительного намагничивания образцов в поле $8 \cdot 10^{5} \mathrm{~A} / \mathrm{m}$, на рис. 6 участки спектров ФМР и намагниченностей $m(H) / m_{0}$, изменяющиеся в области $H$ от $8 \cdot 10^{5}$ до $5 \cdot 10^{5} \mathrm{~A} / \mathrm{m}$, обрезаны как малоинформативные.

Что касается зависимостей $m / m_{0}$, приведенных на рис. 6, отметим следующие их особенности:

a) при $T>T_{\mathrm{C}}$, т.е. когда частицы находятся в парамагнитном состоянии, намагниченность $m / m_{0}$ практически линейно зависит от $H$, но когда $T$ приближается к $T_{\mathrm{C}}$, она начинает показывать отклонение от линейной зависимости (см. зависимость $m / m_{0}$ при $T=306 \mathrm{~K}$ );

b) при $T<T_{\mathrm{C}}$ частицы становятся ферромагнитными, но их зависимости $m / m_{0}$ описываются формулой Ланжевена, что указывает на проявление суперпарамагнитного поведения наночастиц;

c) ансамбли ферромагнитных наночастиц Gd не проявляют никакой коэрцитивности вплоть до гелиевых температур [20]; в области $T_{\mathrm{C}}$ у них одновременно происходит магнитный и ориентационный переходы [10]; в результате ниже $T_{\mathrm{C}}$ одноосные наночастицы $\mathrm{Gd}$ $(K>0)$ приобретают анизотропию типа „легкая плоскость“ $(K<0)$, поэтому они всегда должны перемагничиваться без гистерезиса [21].

По спектрам ФМР переход наночастиц Gd в ферромагнитное состояние проявляется более четко. Он сопровождается, главным образом, сдвигом по $H$ линии ФМР и искажением ее формы. Из приведенных на рис. 6 зависимостей $P(H)$ видно, что наряду с ростом интенсивности спектра ФМР при охлаждении образцов ниже $T_{\mathrm{C}}$ (т.е. когда ЭПР переходит в $Ф М$ ), максимум резонансного поглощения начинает сдвигаться в сторону малых магнитных полей. Кроме того, с понижением температуры растет ширина линии ФМР. При этом уширение происходит несимметрично, в основном за счет плавного сдвига в сторону меньших магнитных полей левого спадающего участка резонансной линии.

Влияние температуры на резонансное поле, которое экспериментально определялось по расположению $H_{m}$ на оси $H\left(H_{m}-\right.$ магнитное поле, соответствующее максимуму линии ФМР), и на ширину линии $\Delta H$ приведены на рис. 7 при изменении $T$ в области $265<T<320 \mathrm{~K}$ для частиц $d=64 \mathrm{~nm}$, а на вставке для $d=28 \mathrm{~nm}$. Видно, что в парамагнитной области $\Delta H$ слабо растет при изменении $T$ от $320 \mathrm{~K}$ до $T_{\mathrm{C}}=293 \mathrm{~K}$. Но при $T<T \mathrm{C}$ зависимости $\Delta H(T)$ для обоих размеров наночастиц изменяется по закону, близкому к линейному, который 


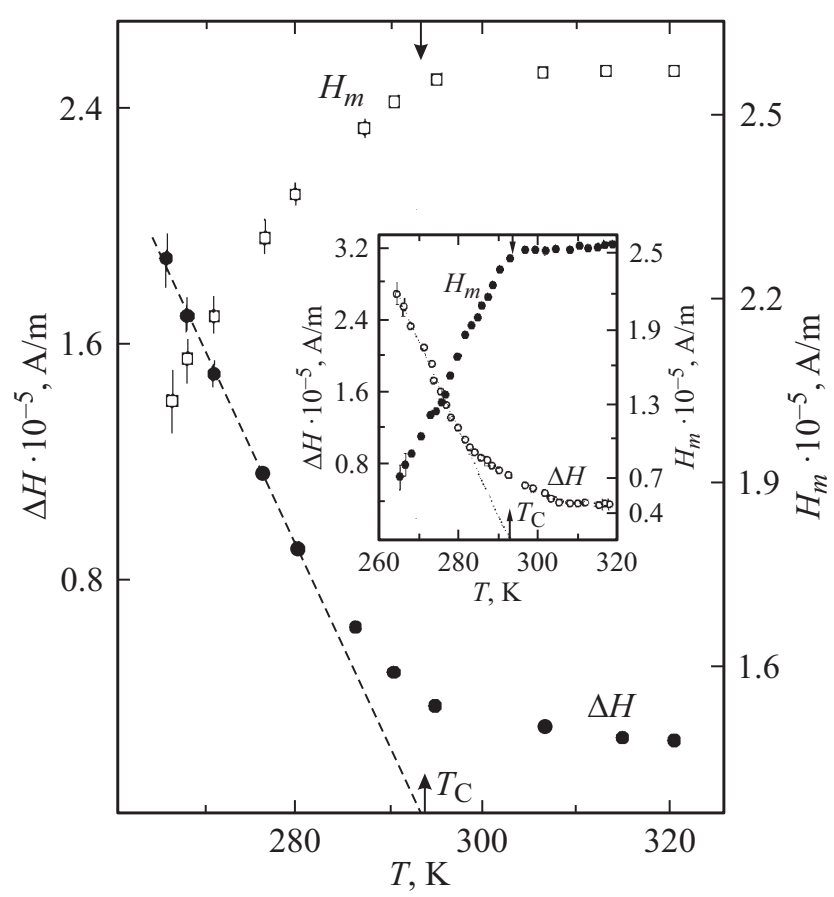

Рис. 7. Зависимости ширины $\Delta H$ и сдвига резонансного поля $H_{m}$ спектра ФМР в ансамбле наночастиц $\mathrm{Gd} d=64 \mathrm{~nm}$ от температуры вблизи $T_{\mathrm{C}}$. На вставке: те же зависимости для ансамбля наночастиц $d=28 \mathrm{~nm}$.

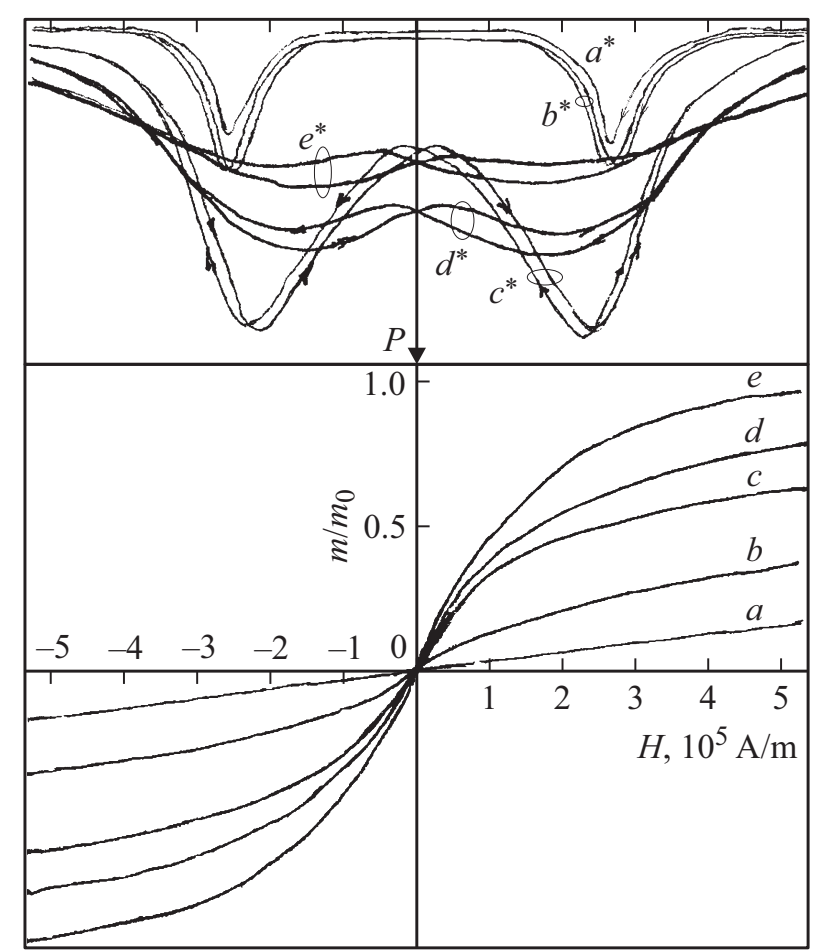

Рис. 8. Изменение намагниченности $m(H)$ и спектра ФМР ансамбля наночастиц гадолиния $d=47 \mathrm{~nm}$ при изменении магнитного поля от $+8 \cdot 10^{5} \mathrm{~A} / \mathrm{m}$ до $-8 \cdot 10^{5} \mathrm{~A} / \mathrm{m}$ и обратно до $+8 \cdot 10^{5} \mathrm{~A} / \mathrm{m}$ при следующих температурах, К: $a-317, b-$ $302, c-286, d-276, e-268$. пересекает ось температур рядом с $T_{\mathrm{C}}$ (см. рис. 7 и вставку).

Из зависимости $H_{m}(T)$, которые также представлена на рис. 7 и на его вставке, видно, что в области температур выше $T_{\mathrm{C}}$ максимум резонансной линии слабо зависит от температуры. Однако при $T<T_{\mathrm{C}}$ обе зависимости $H_{m}(T)$ показывают явно выраженный спад.

Рассмотрим другую особенность ФМР в наночастицах $\mathrm{Gd}$, которую впервые продемонстрировал рис. 4. Она связана с проявлением гистерезиса в спектрах ФМР, имеющих вид зависимостей $P(H)$. Гистерезис четко проявляется при регистрации поглощения СВЧ мощности в результате перемагничивания ансамблей наночастиц в поле от $8 \cdot 10^{5}$ до $-8 \cdot 10^{5} \mathrm{~A} / \mathrm{m}$ и обратно. Влияние температуры на такой гистерезис демонстрируют также зависимости $P(H)$, приведенные на рис. 8 для пяти различных температур. Гистерезисы $P(H)$ обнаружены у всех исследованных размеров наночастиц Gd, находящихся в ферромагнитном состоянии. Например, на рис. 4 показаны гистерезисные зависимости $P(H)$ для наночастиц размером $89 \mathrm{~nm}(T=162 \mathrm{~K})$, а на рис. 8 приведены зависимости $P(H)$ для наночастиц размером $47 \mathrm{~nm}$ при дискретном изменении температуры от 320 (рис. $8, a$ ) до $258 \mathrm{~K}$ (рис. $8, e$ ).

Приведенные на рис. 4 и 8, синхронно записанных со спектрами ФМР зависимости намагниченности $m(H)$ при разных температурах никакого гистерезиса не показали.

Характерным является то, как видно из рис. 8, $a$, находящиеся в парамагнитном состоянии наночастицы Gd не имеют никакого гистерезиса как по полю $H$, так и по амплитуде линий ЭПР. Но как только их температура падает ниже $T_{\mathrm{C}}$, то сразу начинают возникать хотя и слабые, но в то же время четко регистрируемые проявления гистерезиса (рис. 8, $b$ ). Вначале это проявляется, главным образом, в сдвиге резонансных линий ФМР прямого (убывающего по величине) магнитного поля $H$ относительно обратного (увеличивающего по величине) поля $H$. При дальнейшем понижении температуры наночастиц Gd начинает изменяться сам характер гистерезиса. Во-первых, происходит уширение спектра ФМР настолько, что становится трудно его регистрировать ниже $250 \mathrm{~K}$. Это видно из сравнения записи спектров ФМР наночастиц, обозначенных на рис. 8 как $c, d$ и $e$. Во-вторых, максимумы линии ФМР, соответствующие координатам $H_{m}$ и $-H_{m}^{*}$ на оси магнитного поля, тоже размывается сильно. В результате положение $H_{m}$ и $-H_{m}^{*}$ на шкале $H$ можно установить только с большой погрешностью.

\section{3. Обсуждение результатов исследования}

Выше экспериментально было установлено влияние температуры на спектр ФМР в наночастицах $\mathrm{Gd}$, в частности, на ширину линии $\Delta H$ и резонансное поле 
$H_{m}$ при изменении $T$ в области $320-265 \mathrm{~K}$. Такие зависимости $\Delta H(T)$ и $H_{m}(T)$ приведены на рис. 7. Из них видно, что $\Delta H$ слабо растет при изменении $T$ от $320 \mathrm{~K}$ до температур немного ниже $T_{\mathrm{C}}$, но при дальнейшем падении температуры $\left(T<T_{\mathrm{C}}\right)$ зависимость $\Delta H(T)$ начинает изменяться как для частиц размером $d=64 \mathrm{~nm}$, так и для $d=28 \mathrm{~nm}$ (вставка на рис. 7) по закону, близкому к линейному

$$
\Delta H(T) \sim\left|T-T_{\mathrm{C}}\right|
$$

Это качественно соответствует зависимости $\Delta H(T) \sim$ $\sim T / H_{m}$, теоретически установленной Гехтом [4] для наночастиц с анизотропией типа „легкая плоскость“, в предположении, что $H_{m} \cdot \mu>k T$ ( $\mu$ - магнитный момент наночастицы, а $H_{m} \sim H_{r}$ ).

Из-за несимметричного уширения линии ФМР за счет сдвига ее левосторонней части в сторону меньших полей, появившегося у наночастиц Gd после перехода их в ферромагнитное состояние, возникли сложности в точном определении резонансного поля $H_{R}$. В то же время максимум резонансной линии $H_{m}$, который качественно отражает зависимость $H_{r}(T)$, удается четко устанавливать. Из приведенной на рис. 7 зависимости $H_{m}(T)$ видно, что в области температур выше $T_{\mathrm{C}}$ максимум резонансной линии $H_{m}$ слабо зависит от $T$. Однако ниже $T_{\mathrm{C}}$ зависимость $H_{m}$ от $T$ демонстрирует явно выраженное падение, тоже близкое к линейному.

Природу несимметричного уширения линии ФМР трудно понять без анализа гистерезиса спектра ФМР при циклическом намагничивании ансамбля ферромагнитных наночастиц $\mathrm{Gd}$, приведенного, например, на рис. 4. Эти зависимости были приведены именно для демонстрации возможностей разработанной экспериментальной установки, предназначенной для одновременной регистрации намагниченности и ФМР на одном и том же образце.

Из зависимостей, приведенных на рис. 4, хорошо видно, что после предварительного намагничивания ансамбля наночастиц $d=89 \mathrm{~nm}$ в поле $8 \cdot 10^{5} \mathrm{~A} / \mathrm{m}$ и последующего циклического перемагничивания, намагниченность изменяется без гистерезиса, в то время как в спектрах ФМР он четко проявляется. Отсутствие гистерезиса в зависимостях $m(H)$ наблюдалось во всех исследованных ансамблях наночастиц Gd с ГПУ структурой.

Сразу отметим, что ранее теоретически [21] было установлено отсутствие гистерезиса при перемагничивании ансамблей однодоменных наночастиц с одноосной анизотропией и отрицательной первой константой анизотропии $\left(K_{1}<0\right)$. Физически это означает следующее: если у однодоменной частицы с ГПУ решеткой и магнитной анизотропией типа „легкая плоскость“, т.е. когда $K_{1}<0$, под воздействием даже очень большого магнитного поля, имеющего произвольное направление относительно гексагональной оси $c$, удается вектор намагниченности вывести из базисной плоскости, то после выключения поля он опять вернется в исходное положение

Что касается гистерезиса спектра ФМР, то было решено экспериментально проверить - не связан ли такой гистерезис в спектрах ФМР с наличием в наночастицах Gd отрицательной магнитной анизотропии $\left(K_{1}<0\right)$, т.е. с проявлением в гистерезисе ФМР какого-либо влияния анизотропии типа „легкая плоскость“ $[11,22]$.

Сравнительную проверку было решено провести экспериментально, используя в качестве модели хорошо изученные однодоменные наночастицы $\gamma-\mathrm{Fe}_{2} \mathrm{O}_{3}$ игольчатой формы. Образец для исследований был изготовлен в виде взвеси таких наночастиц в жидком растворе эпоксидной смолы, в которой они еще до отверждения смолы подверглись магнитному ориентированию вдоль выбранного направления. Объемная концентрация частиц в твердой смоле соответствовала 0.01. Образец для исследований намагниченности и ФМР имел форму плоского диска диаметром $3 \mathrm{~mm}$ и толщиной $0.1 \mathrm{~mm}$. С целью минимизации влияния размагничивающего поля он располагался в резонаторе так, чтобы его основная поверхность была параллельна как внешнему магнитному полю $H$, так и магнитной $\mathrm{CBЧ} \mathrm{компоненте}$ резонатора.

На рис. 9, $a$ приведены гистерезисные кривые намагниченности $m_{\perp}$ и спектр ФМР $A_{\perp}$ ансамбля наночастиц $\gamma-\mathrm{Fe}_{2} \mathrm{O}_{3}$, оси легкого намагничивания которых частично сориентированы перпендикулярно к магнитному полю $H$. На рис. 9, $b$ представлены аналогичные зависимости для этого же образца, но повернутого в резонаторе на $90^{\circ}$ так, что та же доля наночастиц становилась уже ориентированной параллельно полю $H$. Зависимости намагниченностей $m_{\perp}(H)$ и $m_{\|}(H)$, а также ФМР-спектры $A_{\perp}(H)$ и $A_{\|}(H)$ были записаны в условиях циклического намагничивания наночастиц $\gamma-\mathrm{Fe}_{2} \mathrm{O}_{3}$ при изменении магнитного поля от $8 \cdot 10^{5}$ до $-8 \cdot 10^{5} \mathrm{~A} / \mathrm{m}$ и обратно. На рис. 9, $a$ и $b$ зависимости $m_{\perp}(H)$ и $m_{\|}(H)$, а также $A_{\perp}(H)$ и $A_{\|}(H)$ представлены в усеченном виде. Поле $H$ „обрезано“ до уровня $\pm 3 \cdot 10^{5} \mathrm{~A} / \mathrm{m}$. Видно, что все они имеют гистерезис, различающийся по своему характеру. Например, из зависимостей $m_{\perp}(H)$ и $m_{\|}(H)$ следует, что коэрцитивная сила этого образца заметно отличаются: ${ }^{\perp} H_{\mathrm{c}} \approx 0.25 \cdot 10^{5} \mathrm{~A} / \mathrm{m}$, a ${ } H_{\mathrm{c}}=0.35 \cdot 10^{5} \mathrm{~A} / \mathrm{m}$. Отличаются также их остаточные намагниченности: ${ }^{\perp} j_{r}=0.39$ и $\| j_{r}=0.67$. Для сравнения отметим, что коэрцитивность ансамблей наночастиц Gd близка к нулю $\left(j_{r}<0.03\right.$; $\left.H_{\mathrm{c}}<10^{3} \mathrm{~A} / \mathrm{m}\right)$. Если учесть реальную погрешность при определении величин $j_{r}$ и $H_{\mathrm{c}}$, то можно считать, что коэрцитивность у ансамблей наночастиц $\mathrm{Gd}$ практически отсутствует.

Из сравнения спектров ФМР в ансамблях ферромагнитных частиц $\mathrm{Gd}$ и $\gamma$ - $\mathrm{Fe}_{2} \mathrm{O}_{3}$ можно отметить некоторое подобие в их гистерезисных спектрах, хотя у наночастиц Gd отсутствует гистерезис в намагниченности, а у образцов, содержащих игольчатые наночастицы оксида железа, такой гистерезис явно имеет место. При этом у частиц $\gamma-\mathrm{Fe}_{2} \mathrm{O}_{3}$ вид гистерезисных спектров ФМР 

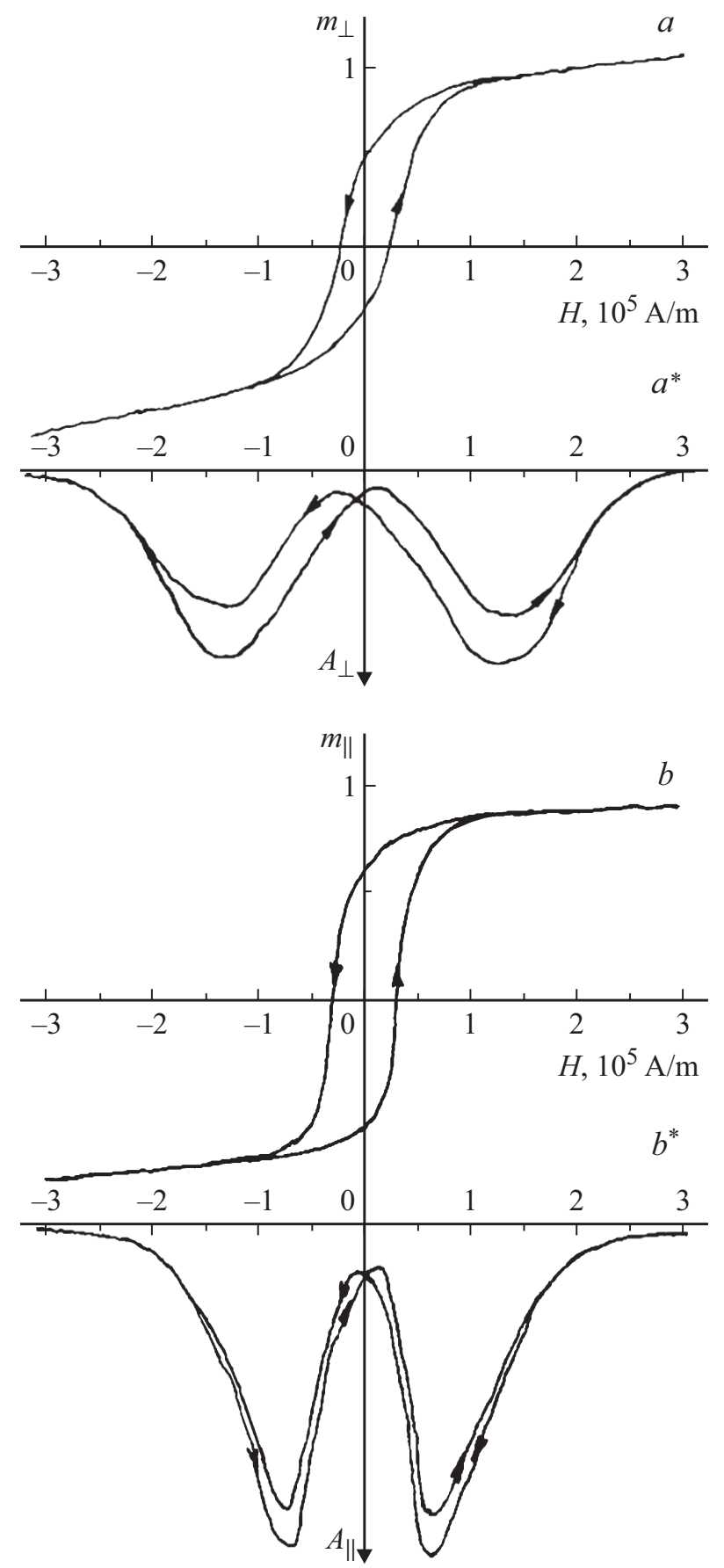

Рис. 9. Изменение намагниченности $m(a)$ и спектра ФМР $b$ в ансамбле игольчатых однодоменных частиц $\gamma-\mathrm{Fe}_{2} \mathrm{O}_{3}$ в результате перемагничивания его при $T=294 \mathrm{~K}$ на участке магнитного поля $\pm 3 \cdot 10^{5} \mathrm{~A} / \mathrm{m}$ (хотя полный цикл перемагничивания образцов соответствовал $\pm 8 \cdot 10^{5} \mathrm{~A} / \mathrm{m}$.)

зависит от ориентации осей легкого намагничивания частиц вдоль магнитного поля (ср. зависимости $A_{\perp}(H)$ и $A_{\|}(H)$ соответственно на рис. $9, a^{*}$ и $\left.9, b^{*}\right)$. Например, у ансамбля одноосных частиц с преобладающей ориентацией своих осей перпендикулярно к полю $H$ насыщение намагниченности $m_{\perp}(H)$ при увеличении $H$ происходит медленно, а спектры ФМР сильно уширены
$\left(\Delta H_{\perp} \sim 1,5 \cdot 10^{5} \mathrm{~A} / \mathrm{m}\right)$. У того же ансамбля частиц, у которого после поворота его на $90^{\circ}$ та же доля магнитных моментов частиц ориентирована параллельно с полем $H$, приближение к насыщению намагниченности $m_{\|}(H)$ идет быстрее, и $\Delta H_{\|} \approx 0.8 \cdot 10^{5} \mathrm{~A} / \mathrm{m}$.

Здесь уместно отметить отличительные особенности в зависимостях от $H$ намагниченности частиц $\gamma-\mathrm{Fe}_{2} \mathrm{O}_{3}$ и их спектров ФМР, чтобы затем это использовать для анализа гистерезиса у наночастиц гадолиния.

Гистерезисная зависимости $m_{\perp}(H)$ и $m_{\|}(H)$ у частиц $\gamma-\mathrm{Fe}_{2} \mathrm{O}_{3}$ по два раза пересекают ось $H$ в точках $\pm H_{\mathrm{c}}$ (см. рис. 9, $a$ и $b$ ). В этих точках намагниченность ансамбля обращается в ноль, так как сумма проекций на направление $H$ магнитных моментов одной половины частиц в ансамбле сохраняет еще направление вдоль положительного поля $H$, а проекции магнитных моментов другой половины уже направлены вдоль отрицательного магнитного поля. Из-за сложения этих вкладов в точках $\pm H_{\mathrm{c}}$ и возникает нулевая намагниченность.

Природа гистерезисных спектров ФМР в частицах $\gamma-\mathrm{Fe}_{2} \mathrm{O}_{3} \quad\left(A_{\perp}(H)\right.$ и $A_{\|}(H)$ на рис. 9, $a^{*}$ и $\left.b^{*}\right)$ существенным образом отличается от природы гистерезиса намагниченности $\left(m_{\perp}(H)\right.$ и $m_{\|}(H)$ на рис. 9, $a$ и $\left.b\right)$. Это связано с различием их происхождения. Если намагниченность $m$ представляет собой просто сумму всех проекций магнитных моментов частиц ансамбля на направление магнитного поля $H$, то в суммарный спектр ФМР вносят вклад только те частицы $\gamma-\mathrm{Fe}_{2} \mathrm{O}_{3}$, у которых реализуется условие резонансного поглощения высокочастотной энергии. Это условие для $i$-ой однодоменной частицы $\gamma-\mathrm{Fe}_{2} \mathrm{O}_{3}$ представим в упрощенной виде

$$
\begin{gathered}
\omega_{0}=\gamma\left|{ }^{i} \mathbf{H}_{\mathrm{eff}}-{ }^{i} N \cdot \mathbf{M}_{c}\right|_{H}, \\
{ }^{i} \mathbf{H}_{\mathrm{eff}}=H+{ }^{i} H_{\mathrm{an}}+{ }^{i} \mathbf{H}_{\mathrm{loc}},
\end{gathered}
$$

где $\left|{ }^{i} \mathbf{H}_{\mathrm{eff}}-{ }^{i} N \cdot \mathbf{M}_{s}\right|_{H}-$ проекция магнитного поля внутри $i$-частицы на направление поля $\mathbf{H},{ }^{i} \mathbf{H}_{\mathrm{eff}}-$ сумма магнитных полей, действующих на $i$-ю частицу; $\mathbf{H},{ }^{i} \mathbf{H}_{\mathrm{an}}$, $\mathbf{M}_{s}$ - соответственно внешнее поле, поле магнитной анизотропии и намагниченность насыщения частицы, которые не зависят от внешнего поля $H ;{ }^{i} \mathbf{H}_{\mathrm{loc}}-$ магнитное поле, действующее на $i$ - частицу от ближайших соседей, $\omega_{0}-$ резонансная частота; $\gamma-$ гиромагнитное отношение, ${ }^{i} N$ - размагничивающий фактор.

ФМР в принципе реализуется только при условии, когда поляризуемость высокочастотного поля $\mathbf{h}$ перпендикулярна направлению внешнего поля Н. С учетом этого создавалась и экспериментальная методика ФМР, т. е. она должна тоже удовлетворять условию

$$
\mathbf{h} \cdot \sin \left(\omega_{0} \cdot t\right) \perp \mathbf{H} \text {. }
$$

В реальных ансамблях однодоменных частиц оси легкого намагничивания хаотично направлены в пространстве. В них всегда существует некоторая доля частиц, которые удовлетворяют соотношениям (3) и (5), и поэтому в определенной области значений $H$, вплоть 
$H=0$ и даже при небольших отрицательных значениях $H$ в этих группах частиц может происходить резонансное поглощение высокочастотной энергии. Все это хорошо подтверждается гистерезисными зависимостями $A_{\perp}(H)$ и $A_{\|}(H)$, приведенными на рис. $9, a^{*}$ и $b^{*}$ для анизотропных частиц $\gamma-\mathrm{Fe}_{2} \mathrm{O}_{3}$.

Теперь можно вернуться к объяснению гистерезиса в спектре ФМР наночастиц Gd. Принимая во внимание, что частицы Gd имеют форму правильных шариков и поэтому у них размагничивающее поле равно нулю, то соотношение (3) для таких наночастиц приобретает более простой вид

$$
\omega_{0}=\gamma\left|{ }^{i} \mathbf{H}_{\mathrm{eff}}\right|_{\mathbf{H}} .
$$

Согласно соотношению (4), ${ }^{i} \mathbf{H}_{\mathrm{eff}}$ преобразуется таким образом

$$
{ }^{i} \mathbf{H}_{\mathrm{eff}}=\mathbf{H}+\mathbf{H}_{\mathrm{an}}+{ }^{i} \mathbf{H}_{\mathrm{loc}} .
$$

Здесь обозначения $\mathbf{H}, \mathbf{H}_{\mathrm{an}}$, и ${ }^{i} \mathbf{H}_{\mathrm{loc}}$ аналогичны тем, которые использованы в соотношениях в (3) и (4).

Для сферических наночастиц $\mathrm{Gd}$, имеющих ГПУ структуру, энергию магнитной анизотропии можно записать в виде разложения в ряд по степеням $\sin ^{2} \theta[11,22]$ :

$$
U_{\text {an }}=K_{1} \sin ^{2} \theta+K_{2} \sin ^{4} \theta+K_{3} \sin ^{6} \theta .
$$

Сразу допускаем, что вблизи $T_{\mathrm{C}}$ магнитной анизотропией можно вообще пренебречь. Это вытекает из следующего. Ниже $T_{\mathrm{C}}$ у наночастиц $\mathrm{Gd}$ одновременно происходят два перехода: магнитный и ориентационный [10]. Частица Gd в области $T_{\mathrm{C}}$ меняет знак первой константы $\left(K_{1} \rightarrow-K_{1}\right)$ и приобретает анизотропию типа „легкая плоскость“. Ее магнитный момент теперь становится параллельным базисной плоскости и может спонтанно изменять свое направление от 0 до $360^{\circ}$. Следующие константы $K_{2}$ и $K_{3}$ в разложении энергии анизотропии в принципе должны мешать направлению легкого намагничивания стать параллельным базисной плоскости. Но они вблизи $T_{\mathrm{C}}$ настолько малы, что неспособны это сделать (зависимости $K_{2}(T)$ и $K_{3}(T)$ на рис. 4.10.а в ссылке [1]). В конечном итоге наночастицы Gd вблизи $T_{\mathrm{C}}$ проявляют суперпарамагнитное поведение, а условие ФМР (6) упрощается до

$$
\omega_{0}=\gamma\left|\mathbf{H}+{ }^{i} \mathbf{H}_{\mathrm{loc}}\right|_{\mathbf{H}} .
$$

Природа поля ${ }^{i} H_{\text {loc }}$ связана с неоднородным распределением наночастиц по образцу, т.е. с наличием кластеров из наночастиц в обьеме образца. Естественно предположить, что ${ }^{i} H_{\text {loc }}$ как-то должно зависеть от внешнего поля $\mathbf{H}$, так как величина и направление этого поля определяют степень ориентации магнитных моментов в кластере наночастиц $\mathrm{Gd}$, окружающих $i$-ю частицу.

Из соотношения (9) вытекает важное следствие: от разброса величины и направления ${ }^{i} H_{\text {lok }}$ зависят все основные характеристики спектра ФМР в ансамбле наночастиц Gd, включая зависимость от температуры ширины линии ФМР и вид гистерезиса. В большом магнитном поле, с которого начинается регистрация спектра ФМР ниже $T_{\mathrm{C}}$, каждый кластер намагничивается до насыщения и создает на $i$-й наночастице поле ${ }^{i} H_{\text {lok }}$ в дополнение к внешнему магнитному полю $H$. В результате уменьшения $H$ интенсивность линии ФМР достигает максимального значения вблизи $H=H_{m}$, а затем начинает падать (см., например, рис. 4). При этом с понижением температуры $H_{m}$ начинает уменьшаться, но увеличивается поглощение СВЧ энергии в нулевом магнитном поле. Более того, в области отрицательного поля $H$ по сравнению с „положительным“ магнитным полем, с которого начинается регистрация спектра $\Phi \mathrm{MP},\left|H_{m}^{*}\right|$ увеличивается, а интенсивности линии ФМР при $H=-H_{m}^{*}$ падает (см., например, рис. 4 и 8).

Наконец, несколько слов о межчастичных взаимодействиях внутри ансамблей, один из которых состоит из суперпарамагнитных наночастиц $\mathrm{Gd}$, а второй из игольчатых частиц $\gamma-\mathrm{Fe}_{2} \mathrm{O}_{3}$. Общим для этих ансамблей является то, что каждый из них включает однодоменные наночастицы, имеющие спонтанную намагниченность, которая в гадолинии в 6 раз больше, чем у $\gamma-\mathrm{Fe}_{2} \mathrm{O}_{3}$. И если ансамбль наночастиц $\gamma-\mathrm{Fe}_{2} \mathrm{O}_{3}$ состоит из частиц с высокой коэрцитивностью, то ансамбль наночастиц $\mathrm{Gd}$ как вблизи $T_{c}$, так и в области гелиевых температур ведет себя как суперпарамагнетик. При этом энергия взаимодействия между наночастицами Gd почти в 30 раз больше, чем у частиц $\gamma-\mathrm{Fe}_{2} \mathrm{O}_{3}$.Поэтому вероятность возникновения кластеров в ансамбле наночастиц $\mathrm{Gd}$ довольна высока. Но такие кластеры не способны придать коэрцитивность всему ансамблю наночастиц Gd из-за несоответствия времен релаксации наночастиц со временем регистрации намагниченности их ансамбля. Действительно, время регистрации намагниченности обычно осуществляется в течение $1-10^{2} \mathrm{~s}$. За это время в нулевом поле каждая наночастица $\mathrm{Gd}$ может хотя бы раз поменять направление своего магнитного момента на противоположное, что допустимо для суперпарамагнитных наночастиц. У ансамбля наночастиц никогда не проявится коэрцитивность.. В то же время такая медленная релаксация магнитного момента наночастиц неспособна повлиять на интенсивности спектра ФМР.

\section{Заключение}

В завершение сделаем два основных вывода по результатам исследования наночастиц $\mathrm{Gd}$.

1. Исследованы намагниченность и ЭПР в наночастицах Gd размером от 28 до $89 \mathrm{~nm}$. При температуре $T_{c}=293 \pm 1 \mathrm{~K}$ в частицах $\mathrm{Gd}$ происходит одновременно магнитный и ориентационный переходы. Установлено, что $g$-фактор для исследованных наночастиц $\mathrm{Gd}$ в парамагнитном состоянии не зависит от их размера и кристаллической структуры. Он практически совпадает (в пределах погрешности их определения) с теоретическим значением $g=2.00$ для $4 f$-электронов иона $\mathrm{Gd}^{+3}$. 
2. Ниже $T_{\mathrm{C}}$ вид спектров ФМР в наночастицах $\mathrm{Gd}$ не зависят от их размера. При снижении температуры они уширяются и сдвигаются в направление нулевого поля. При циклическом перемагничивании ансамблей наночастиц $\mathrm{Gd}$ в спектрах ФМР проявляется гистерезис, природа которого не связана с коэрцитивностью наночастиц. Предполагается, что он обусловлен неоднородным распределением частиц в образцах.

Авторы выражают благодарность за помощь в работе И.П. Лаврентьеву Ал.П. Александрову, В.А. Бостанджияну, А.Н. Костыгову, Д.А. Кулакову, А.В. Петиновой, А.Е.Петрову и В.В. Шевченко, а также Д.В. Беркову Д.В. за полезные дисскусии.

\section{Список литературы}

[1] Тейлор К., Дарби М. Физика редкоземельных соединений. М.; Мир, 1974.

[2] Huber D.L. // J. Phys. Chem. Solids. 1971. Vol. 32. P. $2145-2153$

[3] Малеев С.В. // ЖЭТФ. 1974. Т. 66. С. 1809-1815.

[4] Гехт Р.С. // ФММ. 1983. Т. 55. С. 225-229.

[5] Burgardt P., Seehra M.S. // Phys. Rev. 1977. Vol. B16. N 5. P. $1802-1807$.

[6] Андерс А.Г., Белозеров Д.П., Спольник А.И. // ФНТ. 1977. T. 3. C. $1538-1542$.

[7] Пул Ч. Техника ЭПР-спектроскопии. М.: Мир. 1970. C. 448.

[8] Александров И.А., Матленкова И.Ю., Абрамчук С.С., Солодовников С.П., Ходак А.А., Зезин С.Б., Александров А.И. // ЖТФ. 2013. Т. 83. Вып. 3. С. 66-70.

[9] Петинов В.И. // ЖФХ. 2016. Т. 90. Вып. 7. С. 1-6.

[10] Петинов В.И. //ЖТФ. 2017. Т. 87. Вып. 6. С. 867-874.

[11] Ландау Л.Д., Лифшии Е.М. Электродинамика сплошных сред. М.: Наука, 1982. С. 46.

[12] Tishin A.M., Spichkin Y.I. Magnetocaloric Effect and its Applications. IOP Publishing Ltd.Bristol, 2003. 475 p.

[13] Hou S., Tong S., Zhou J., Bao G. // Nanomedicine. 2012. V. 7. N 2. P. $211-8$.

[14] Zhang Hong-Wu, Wang Li-Qin, Xiang Qing-Feng at. all. // Biomaterials. 2014. Vol. 35. N 1. P. 356-367.

[15] Кондрашина O.B. // Гадолиний в нейтрон-захватной терапии. Металлоорганические магнитные наночастицы как система адресной доставки Gd к клеткам-мишеням опухолей. Германия. LAP Lambert Academic Pablishing, 2014. $188 \mathrm{p}$.

[16] Zimmerman R. Nuclear Medicine Radioactivity for diagnosis and Therapy. EDP Science. 2007. 173 p.

[17] Ген М.Я., Миллер А.В. // Поверхность. 1983. Т. 2. C. $50-154$.

[18] Бостанджсян В.А. // Пособие по статистическим распределениям. Черноголовка. РИО. ИПХФ РАН. 2013. C. $535-556$.

[19] Chiba Y. Nakamura A. // J. Phys. Sos. Japan.1970. Vol. 29. P. 792.

[20] Морозов Ю.Г., Костыгов А.Н., Петинов В.И., Чижсов П.Е. // ФНТ. 1975. Т. 1. № 11. С. 1407-1408.

[21] Петинов В.И. // ЖТФ. 2014. Т. 84. Вып. 1. С. 8-17.

[22] Horner H., Varma C.M. // Phys. Rev. Lett. 1968. Vol. 20. N 16. P. $845-846$. 